\title{
Caracterização de sedimento proveniente de dragagem de canais pluviais do município de Salvador-BA visando sua utilização em cerâmica estrutural
}

\section{(Characterization of sediment from the dredging of stormwater channels in the city of Salvador-BA aiming to use in structural ceramics)}

\author{
O. C. Santos ${ }^{1,2}$, S. B. Breitenbach ${ }^{1,2}$, R. E. Coelho ${ }^{1}$, J. C. S. Andrade ${ }^{3}$, J. C. C. Sales Jr. ${ }^{3}$, \\ C. A. Paskocimas ${ }^{2}$, A. E. Martinelli', R. M. Nascimento ${ }^{2}$ \\ ${ }^{1}$ Instituto Federal de Educação, Ciência e Tecnologia da Bahia, R. Emidio Santos s/n, Salvador, BA \\ ${ }^{2}$ Programa de Pós-Graduação em Ciência e Engenharia de Materiais, \\ Universidade Federal do Rio Grande do Norte, Natal, $R N$ \\ ${ }^{3}$ Departamento de Engenharia de Materiais, Faculdade de Tecnologia, Universidade Federal do Amazonas, \\ Av. Rodrigo Otávio Jordão Ramos 3000, Manaus, AM \\ engcruz@ig.com.br,silviabb@ifba.edu.br,rodrigoecoelho@gmail.com,jean.engmateriais@gmail.com, \\ jccalado@gmail.com,paskocimas@uol.com.br,aemart@uol.com.br,rubensmaribondo@gmail.com
}

\begin{abstract}
Resumo
Este trabalho teve como objetivo caracterizar o sedimento proveniente de dragagem de canais pluviais (SCP), do município de Salvador-BA, visando sua máxima substituição pela argila em cerâmica estrutural, uma vez que essa mistura binária faz parte do projeto piloto da massa padrão, na pesquisa da formulação de blocos intertravados cerâmicos. Inicialmente o sedimento foi submetido aos ensaios de índice de plasticidade, analise química por fluorescência de raios X, análise mineralógica por difração de raios X, analise térmica e granulométrica. A morfologia do material foi analisada utilizando-se microscopia eletrônica de varredura, acompanhada de espectroscopia de energia dispersiva. Em seguida foram feitas adições de sedimento (SCP) a uma argila do município de Candeias-BA, nas proporções de 10, 20, 30 e 40\% em massa. Foram preparados corpos de prova por prensagem uniaxial nas dimensões $60 \mathrm{~mm}$ x $20 \mathrm{~mm}$, com pressão de compactação de $25 \mathrm{MPa}$, sendo que o material foi umidificado com $8 \%$ de água. A queima foi realizada em forno resistivo a 850,950 e $1050{ }^{\circ} \mathrm{C}$, com taxa de aquecimento de $5{ }^{\circ} \mathrm{C} / \mathrm{min}$. As propriedades avaliadas foram retração linear, absorção de água e módulo de ruptura à flexão. Os resultados indicaram que é possível a utilização do SCP em cerâmica estrutural, mediante os pré-requisitos exigidos em normas, na fabricação de telhas, blocos de vedação e tijolos. Palavras-chave: cerâmica, sedimento de canais, propriedades mecânicas.
\end{abstract}

Abstract

The aim of this study was to characterize sediment from the dredging of stormwater channels (SCP) in the city of Salvador, Bahia, aiming its maximum replacement by clay in structural ceramics, since this binary mixture is part of the pilot project of the standard mass, in the research of interlocked block ceramic formulation. Initially, the sediment was submitted to the following tests: plasticity index; chemical analysis by X-ray fluorescence; mineralogical analysis by X-ray diffraction; thermal and particle size analyses. The morphology of the material was analyzed by scanning electron microscopy, coupled with energy dispersive spectroscopy. Then, sediment (SCP) was added to clay from the municipality of Candeias, Bahia, in the proportions of 10, 20, 30 and $40 \mathrm{wt} \%$. Specimens were prepared by uniaxial pressing in dimensions of $60 \mathrm{~mm} \times 20 \mathrm{~mm}$, with compacting pressure of $25 \mathrm{MPa}$, and the material was humidified with $8 \%$ of water. Firing was conducted in resistive furnace at temperatures of 850,950 and 1050 ${ }^{\circ} \mathrm{C}$, with $5{ }^{\circ} \mathrm{C} / \mathrm{min}$ heating rate. The properties evaluated were: linear shrinkage; water absorption and modulus of rupture. The results indicated the possibility of using SCP in structural ceramics by the prerequisites required in standards, in the manufacture of tiles, sealing blocks and bricks.

Keywords: ceramics, sediment, mechanical properties.

\section{INTRODUÇÃO}

A cidade de Salvador, com aproximadamente 262 canais, responsáveis pelo escoamento de águas pluviais, esses na sua maioria por não serem revestidos, necessitam de intervenção todos os anos, gerando uma quantidade significativa de sedimentos (lama dragada), em torno de 250 mil metros cúbicos, sendo imperativa uma metodologia adequada para sua destinação final. A busca de um destino final para os resíduos gerados tem sido intensificada em todo o mundo, 
tornando uma das grandes premissas das indústrias, para que possam estar em conformidade com as normas de proteção ao meio ambiente [1]. De acordo com a norma ABNT-NBR 10004/2004, resíduos são materiais no estado sólido ou semissólido, que resultam de atividades de origem industrial, doméstica, hospitalar, comercial, agrícola, de serviços e de varrição [2]. Os sedimentos de canais pluviais são materiais oriundos da limpeza e dragagem de canais, espécie de lama de cor escura com odor de médio a forte de esgoto. Trata-se de material de aluvião, transportado e depositado por ação hidráulica, ou de solo alterado formado in situ a partir da rocha subjacente, responsável pela obstrução dos sistemas de drenagem e pela carga em suspensão de argila, que é transportada para as praias, em época de chuvas [3].

Se de um lado, a atividade de limpeza e desobstrução dos canais é necessária, por outro é também uma grande geradora de sedimentos (lama dragada), com forte impacto no meio ambiente e de difícil definição quanto ao local apropriado para realizar o despejo, uma vez que existem representações de órgãos ambientais e legislações, a exemplo da resolução do Conselho Nacional do Meio Ambiente (CONAMA) [4], que são utilizadas como critério para análise do sedimento dragado, a fim de orientar o gerenciamento de disposição desse material no procedimento de licenciamento ambiental, quanto ao seu destino para aterros sanitários. Por outro lado, as indústrias cerâmicas da Bahia apresentam produção total da ordem de 195 mil milheiros/mês, sendo 167 mil de blocos (86\%) e 28 mil de telhas (14\%), o que a coloca em sexto lugar no cenário da produção nacional, com uma participação de $3,7 \%$. O consumo de argila é da ordem de $445.000 \mathrm{t} / \mathrm{mês}$, para produzir $370.000 \mathrm{t}$ de produto final, com uma média de $1,9 \mathrm{~kg} /$ milheiro, ligeiramente inferior à média nacional, indicando a produção de peças menores [5], tendo um polo na Região Metropolitana de Salvador (RMS), com grande reserva de argila, na ordem de 188 milhões de toneladas, segundo dados da Companhia Baiana de Pesquisa Mineral (CBPM) [6].

Diante dessas considerações, o uso desse resíduo na massa argilosa pode passar a ser mais uma fonte de material alternativo a ser empregado na indústria cerâmica, apresentando algumas vantagens, tais como: redução do volume de resíduos que por sua vez vem provocando danos à saúde pública e ao ambiente; otimização do prolongamento de vida útil dos aterros sanitários, e redução do consumo das fontes naturais de argilas utilizadas na produção cerâmica. Neste sentido, este trabalho tem como objetivo caracterizar o sedimento proveniente de dragagem de canais pluviais (SCP) do município de Salvador-BA, visando sua máxima substituição pela argila em massas de cerâmica estrutural, na fabricação de blocos e telhas dentro das especificações técnicas $[7,8]$.

\section{MATERIAIS E MÉTODOS}

Inicialmente foi definido um procedimento para coleta da lama proveniente da dragagem do canal de águas pluviais da RMS, sendo seu respectivo pseudocomponente denominado por sedimento de canais pluviais (SCP). Foram escolhidos seis dos principais canais, e em cada um deles foram coletadas três amostras em locais $1,0 \mathrm{~km}$ equidistantes, com aproximadamente $5 \mathrm{~kg}$ cada amostra. Através de um GPS de navegação de $\pm 2 \mathrm{~m}$ de precisão, foram identificadas as coordenadas geográficas do lugar de coleta, como se mostra na Tabela I. O critério para escolha dos pontos de coleta foi baseado nas possibilidades de maior contaminação, por se encontrar próximos de indústrias, clínicas, hospitais, vilas ribeirinhas entre outros. A amostragem foi coletada com o auxílio de uma escavadeira hidráulica e em alguns pontos de difícil acesso com a utilização de uma pá ou trado manual.

Após a remoção cuidadosa de vegetais e outros detritos presentes na superfície, as amostras foram coletadas a uma profundidade média de $40 \mathrm{~cm}$, identificadas e, após secagem natural, as amostras de cada canal foram misturadas entre si, quarteadas e depois homogeneizadas importando essa mistura como a amostra representativa daquele canal, totalizando 6 amostras representativas dos canais em estudo. Além das amostras coletadas no próprio canal, verificouse a necessidade de efetuar coleta na área pré-estabelecida pelo Órgão Municipal para destinação final do material dragado (bota-fora). Nesta, foram coletadas 6 amostras que, após secagem natural, foram misturadas entre si, representando essa mistura, como a amostra de sedimentos de canal pluvial (SCP) da RMS. Para validação do processo, a coleta foi realizada no mês de outubro de 2010 e repetida, conservando as condições dos locais de coleta, em abril e outubro de 2011. Após identificação as amostras foram ensacadas individualmente e levadas para o laboratório de cerâmica da UFRN, onde, em estufa elétrica a $110^{\circ} \mathrm{C}$ por 24 $\mathrm{h}$, realizou-se o processo de secagem e posteriormente foram desaglomeradas manualmente com o auxílio de pistilo e almofariz, uma vez que se tratava de uma quantidade pequena visando a caracterização do material, enquanto a amostra representativa dos canais da RMS (SCP) foi desagregada em moinho de bolas por $8 \mathrm{~h}$. Preliminarmente foram realizadas as análises químicas semiquantitativas, por espectroscopia de fluorescência de raios $\mathrm{X}$, obtendo resultados cujas diferenças não foram significativas, mostrando que pode haver estabilidade dessas características. Na Tabela II estão os resultados das análises químicas das amostras S1, S2, S3, S4, S5, S6 e SCP (amostra tipicamente representativa), ilustradas na Fig. 1 por um diagrama ternário do sistema $\mathrm{Al}_{2} \mathrm{O}_{3}-\mathrm{SiO}_{2}-\left(\mathrm{RO}+\mathrm{RO}_{2}+\mathrm{MnO}+\mathrm{SO}_{3}\right)$.

A argila utilizada como massa de referência foi cedida pela Cerâmica Candeias, localizada na RMS, no município de Candeias-BA. Coletada na jazida em forma de torrões que, após secagem natural durante cinco dias, foi ensacada, identificada e levada para o laboratório, onde foi submetida ao processo de secagem em estufa elétrica a $110{ }^{\circ} \mathrm{C}$ por 24 h. Posteriormente a argila foi desaglomerada manualmente com o auxílio de pistilo e almofariz, desagregada em moinho de bolas durante o período de $8 \mathrm{~h}$ e em seguida foi peneirada em malha de 70 mesh (ABNT n ${ }^{\circ} 70$, abertura de $0,210 \mathrm{~mm}$ ).

Com a finalidade de determinar as características químicas, físicas e mineralógicas das matérias-primas 
Tabela I - Localização dos pontos de coleta de amostra dos canais da RMS.

[Table I - Location of sample collection regions of RMS channels.]

\begin{tabular}{|c|c|c|c|c|c|c|}
\hline \multirow{2}{*}{$\begin{array}{l}\text { Bacia hidro } \\
\text { canal }\end{array}$} & \multirow{2}{*}{$\begin{array}{c}\text { Denominação da } \\
\text { amostra }\end{array}$} & \multicolumn{2}{|c|}{ Características } & \multirow[b]{2}{*}{ Amostra } & \multicolumn{2}{|c|}{ Coordenadas geográficas } \\
\hline & & $\begin{array}{c}\text { Extensão } \\
\text { aprox. }\end{array}$ & $\begin{array}{c}\text { Seção média } \\
\text { BxLxH (m) }\end{array}$ & & Abscissa (W) & Ordenada $(\mathrm{S})$ \\
\hline \multirow{4}{*}{$\begin{array}{c}\text { Lucaia / V. } \\
\text { Gama }\end{array}$} & \multirow{4}{*}{ S1 } & \multirow{3}{*}{$5,8 \mathrm{~km}$} & \multirow{3}{*}{$3,6 \times 6,0 \times 2,0$} & A1-01 & $38^{\circ} 29,788^{\prime}$ & $12^{\circ} 59,713^{\prime}$ \\
\hline & & & & A1-02 & $38^{\circ} 29,524^{\prime}$ & $13^{\circ} 00,201^{\prime}$ \\
\hline & & & & A1-03 & $38^{\circ} 28,972^{\prime}$ & $12^{\circ} 58,149^{\prime}$ \\
\hline & & \multirow{3}{*}{$4,5 \mathrm{~km}$} & \multirow{3}{*}{$14 \times 17 \times 2,5$} & A2-01 & $38^{\circ} 26,013^{\prime}$ & $12^{\circ} 58,150^{\prime}$ \\
\hline \multirow[t]{3}{*}{ Rio das Pedras } & \multirow[t]{3}{*}{ S2 } & & & A2-02 & $38^{\circ} 25,709^{\prime}$ & $12^{\circ} 58,424^{\prime}$ \\
\hline & & & & A2-03 & $38^{\circ} 25,556^{\prime}$ & $12^{\circ} 58,534^{\prime}$ \\
\hline & & \multirow{3}{*}{$2,0 \mathrm{~km}$} & \multirow{3}{*}{$2,5 \times 3,0 \times 1,5$} & A3-01 & $38^{\circ} 30,668^{\prime}$ & $12^{\circ} 59,739^{\prime}$ \\
\hline \multirow[t]{2}{*}{ Canela } & \multirow[t]{2}{*}{ S3 } & & & A3-02 & $38^{\circ} 31,221^{\prime}$ & $12^{\circ} 59,702^{\prime}$ \\
\hline & & & & A3-03 & $38^{\circ} 31,478^{\prime}$ & $12^{\circ} 59,571^{\prime}$ \\
\hline \multirow{4}{*}{ Camarajipe } & \multirow{4}{*}{ S4 } & \multirow{4}{*}{$15 \mathrm{~km}$} & \multirow{4}{*}{$15 \times 22 \times 2,8$} & A4-01 & $38^{\circ} 28,596^{\prime}$ & $12^{\circ} 59,481^{\prime}$ \\
\hline & & & & A4-02 & $38^{\circ} 27,027^{\prime}$ & $12^{\circ} 59,783^{\prime}$ \\
\hline & & & & A4-03 & $38^{\circ} 28,046^{\prime}$ & $12^{\circ} 59,687^{\prime}$ \\
\hline & & & & A4-04 & $38^{\circ} 28,474^{\prime}$ & $12^{\circ} 57,139^{\prime}$ \\
\hline \multirow{4}{*}{ Jaguaribe } & \multirow{4}{*}{ S5 } & \multirow{4}{*}{$10 \mathrm{~km}$} & \multirow{4}{*}{$17 \times 23 \times 2,9$} & A5-01 & $38^{\circ} 23,210^{\prime}$ & $12^{\circ} 57,272^{\prime}$ \\
\hline & & & & A5-02 & $38^{\circ} 23,973^{\prime}$ & $12^{\circ} 57,727^{\prime}$ \\
\hline & & & & A5-03 & $38^{\circ} 23,380^{\prime}$ & $12^{\circ} 57,024^{\prime}$ \\
\hline & & & & A5-04 & $38^{\circ} 22,773^{\prime}$ & $12^{\circ} 56,175^{\prime}$ \\
\hline \multirow{3}{*}{$\begin{array}{l}\text { Cobre / São } \\
\text { Bartolomeu }\end{array}$} & \multirow{3}{*}{ S6 } & \multirow{3}{*}{$1,8 \mathrm{~km}$} & \multirow{3}{*}{$2,5 \times 3,0 \times 1,2$} & A6-01 & $38^{\circ} 28,497^{\prime}$ & $12^{\circ} 54,120^{\prime}$ \\
\hline & & & & A6-02 & $38^{\circ} 28,402^{\prime}$ & $12^{\circ} 54,060^{\prime}$ \\
\hline & & & & A6-03 & $38^{\circ} 28,359^{\prime}$ & $12^{\circ} 53,989^{\prime}$ \\
\hline
\end{tabular}

Tabela II - Resultados das análises químicas (\% em massa) dos sedimentos representativos de cada canal. [Table II - Results of chemical analyzes (wt\%) of representative sediments of each channel.]

\begin{tabular}{cccccccc}
\hline Óxido & $\mathrm{S} 1$ & $\mathrm{~S} 2$ & $\mathrm{~S} 3$ & $\mathrm{~S} 4$ & $\mathrm{~S} 5$ & $\mathrm{~S} 6$ & $\mathrm{SCP}$ \\
\hline $\mathrm{Al}_{2} \mathrm{O}_{3}$ & 37,72 & 37,33 & 32,39 & 30,88 & 38,04 & 35,26 & 38,47 \\
$\mathrm{SiO}_{2}$ & 26,32 & 26,36 & 28,74 & 24,81 & 31,14 & 24,39 & 28,37 \\
$\mathrm{Fe}_{2} \mathrm{O}_{3}$ & 15,39 & 15,73 & 17,01 & 18,25 & 11,86 & 16,32 & 15,47 \\
$\mathrm{TiO}_{2}$ & 2,38 & 4,73 & 2,57 & 2,22 & 2,90 & 2,22 & 2,16 \\
$\mathrm{CaO}$ & 0,50 & 3,81 & 0,98 & 2,90 & 0,53 & 2,52 & 1,02 \\
$\mathrm{~K}_{2} \mathrm{O}$ & 0,38 & 0,56 & 0,62 & 0,52 & 0,67 & 0,47 & 1,30 \\
$\mathrm{SO}_{3}$ & 0,22 & 1,44 & 0,93 & 2,03 & 0,36 & 0,35 & 0,46 \\
$\mathrm{MnO}$ & 0,15 & 0,16 & 0,12 & 0,09 & 0,07 & 0,10 & 0,15 \\
$\mathrm{ZrO}$ & 0,13 & 0,61 & 0,26 & 0,17 & 0,24 & 0,12 & 0,04 \\
$\mathrm{P}_{2} \mathrm{O}_{5}$ & 0,07 & 0,77 & 0,72 & 0,30 & 0,10 & 0,18 & 0,24 \\
$\mathrm{ZnO}$ & 0,04 & 0,05 & 0,11 & - & 0,14 & 0,07 & 0,02 \\
$\mathrm{PF}$ & 16,70 & 8,45 & 15,55 & 17,83 & 13,95 & 18,00 & 12,30 \\
\hline
\end{tabular}

realizaram-se as seguintes análises: análise química do SCP, como apresentado, e da argila, pelo método semiquantitativo de espectroscopia de fluorescência de raios X (FRX), utilizando-se o espectrômetro de energia dispersiva EDX720 da Shimadzu, e pela quantificação de perda ao fogo
(PF); índice de plasticidade (IP) pelo método de Atterberg [9, 10], segundo classificação de Caputo; análise mineralógica através do ensaio de difração de raios X (DRX), utilizandose o difratômetro XRD-600 da Shimadzu, operando com radiação de $\mathrm{CuK} \alpha$, varredura de $5^{\circ}$ a $80^{\circ}$ em $2 \theta$ com 


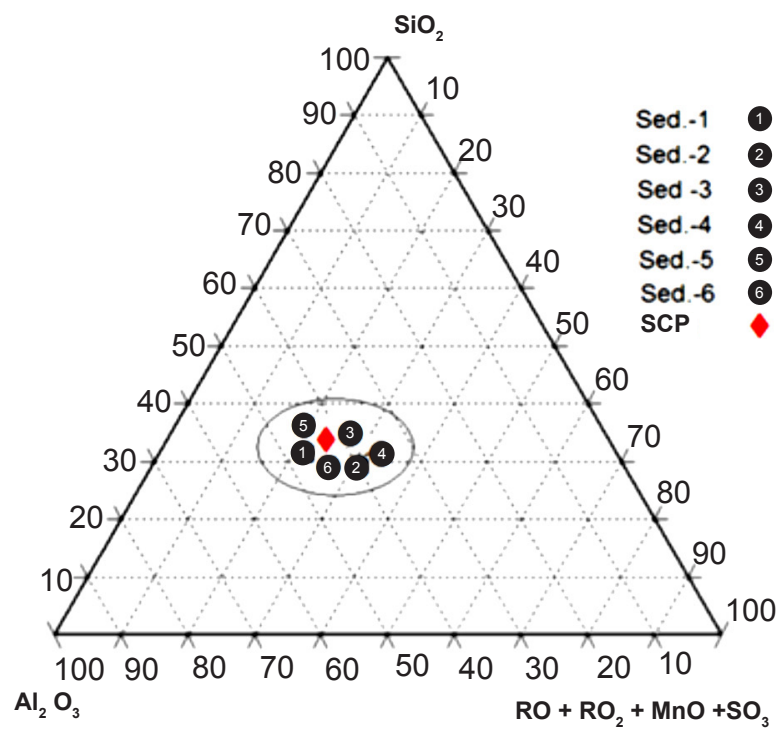

Figura 1: Diagrama ternário do sistema $\mathrm{Al}_{2} \mathrm{O}_{3}-\mathrm{SiO}_{2}-\left(\mathrm{RO}+\mathrm{RO}_{2}\right.$ $+\mathrm{MnO}+\mathrm{SO}_{3}$ ).

[Figure 1: Ternary diagram of the $\mathrm{Al}_{2} \mathrm{O}_{3}-\mathrm{SiO}_{2}-\left(\mathrm{RO}+\mathrm{RO}_{2}+\mathrm{MnO}\right.$ $+\mathrm{SO}_{3}$ ) system.]

velocidade de $2 \% \mathrm{~min}$; análise térmica (TGA e DTA) através do analisador termogravimétrico e diferencial DTG-60 da Shimadzu, operando com atmosfera controlada com gás argônio com vazão de $50 \mathrm{~mL} / \mathrm{min}$, da temperatura ambiente até $1200^{\circ} \mathrm{C}$ com taxa de aquecimento de $10^{\circ} \mathrm{C} / \mathrm{min}$ e análise granulométrica por difração a laser, através do granulômetro 920L da Cilas, na faixa de 0,3 a $400 \mu \mathrm{m}$. A morfologia foi analisada utilizando-se microscopia eletrônica de varredura (MEV) com análise e mapeamento por espectrômetro de energia dispersiva (EDS).

Foram elaboradas cinco formulações com misturas binárias, argila e sedimento (SCP), conforme mostra a Tabela III. Estas composições foram homogeneizadas, a seco, em moinho planetário durante $30 \mathrm{~min}$ e em seguida armazenadas em recipientes plásticos hermeticamente vedados. Os corpos de prova foram confeccionados através de uma matriz de aço com cavidade retangular de dimensões $60 \mathrm{~mm} \times 20 \mathrm{~mm}$, por prensagem uniaxial simples, cuja pressão de compactação foi de $25 \mathrm{MPa}$. Para confecção de cada corpo de prova foram necessários $13 \mathrm{~g}$ de material préumidificado com $8 \%$ em massa de água. Após a extração da matriz, os corpos de prova foram identificados, pesados, medidos, secos em estufa elétrica a $110^{\circ} \mathrm{C}$ por $24 \mathrm{~h}$, medidos e pesados novamente, para daí serem levados ao forno para queima. A queima foi realizada em forno resistivo a 850 , 950 e $1050{ }^{\circ} \mathrm{C}$, com rampa de aquecimento de $5{ }^{\circ} \mathrm{C} / \mathrm{min}$, com patamar em $450{ }^{\circ} \mathrm{C}$ por 30 min, e outro na temperatura máxima por mais $30 \mathrm{~min}$, com resfriamento por convecção natural até a temperatura ambiente.

As propriedades tecnológicas determinadas foram: retração linear de queima, absorção de água e módulo de ruptura à flexão. Durante a queima, a retração é consequência do fenômeno de sinterização. Foram medidos os comprimentos dos corpos de prova após secagem e após a queima, utilizando-se paquímetro Starret com resolução de $0,05 \mathrm{~mm}$. A capacidade de absorção de água do corpo sinterizado está relacionada com a quantidade de água em porcentagem que o corpo absorve após a queima. Os corpos de prova foram submersos, em água destilada, no período de $24 \mathrm{~h}$ e posteriormente pesados em balança digital com precisão de $0,01 \mathrm{~g}$. O módulo de ruptura à flexão determina o valor da tensão que, aplicada ao corpo de prova, causa uma ruptura após o aumento uniforme desta. O comportamento mecânico foi analisado por teste de flexão em três pontos.

Tabela III - Formulação (\% em massa) da mistura binária $($ argila + SCP).

[Table III - Binary mixture formulation (clay + SCP, wt\%).]

\begin{tabular}{cccc}
\hline Formulação & & Argila & SCP \\
\hline Matriz 100\% & MR & 100 & - \\
& MR10 & 90 & 10 \\
Argila + Sedimento de & MR20 & 80 & 20 \\
canais pluviais (SCP) & MR30 & 70 & 30 \\
& MR40 & 60 & 40 \\
\hline
\end{tabular}

\section{RESULTADOS E DISCUSSÃO}

A Tabela IV apresenta algumas características da argila. Pela análise de FRX, verificou-se que na sua composição química havia concentrações significativas de $\mathrm{SiO}_{2}, \mathrm{Al}_{2} \mathrm{O}_{3}$ e $\mathrm{Fe}_{2} \mathrm{O}_{3}$, com médio teor de $\mathrm{K}_{2} \mathrm{O}, \mathrm{TiO}_{2}$ e $\mathrm{MgO}$, e traços nos demais óxidos, a exemplo do $\mathrm{MnO}, \mathrm{ZnO}$ e $\mathrm{SO}_{3}$, cujos percentuais foram menores que $0,06 \%$. O elevado teor de fundente, óxido de ferro $\left(\mathrm{Fe}_{2} \mathrm{O}_{3}=11,94 \%\right)$, que somado aos demais fundentes existentes $\left(\mathrm{MgO}\right.$ e $\left.\mathrm{K}_{2} \mathrm{O}\right)$, totalizou 18,38\% que, além de justificar a sua queima em baixa temperatura entre 900 a $950{ }^{\circ} \mathrm{C}$, contribuiu para reduzir a absorção de água e a porosidade aparente das peças cerâmicas, bem como aumentar a sua resistência mecânica. As fases mineralógicas presentes (Fig. 2a) foram quartzo $\left(\mathrm{SiO}_{2}\right)$ como fase predominante, seguido da caulinita $\left[\mathrm{Al}_{2} \mathrm{Si}_{2} \mathrm{O}_{5}(\mathrm{OH})_{4}\right]$, muscovita $\left[\mathrm{KMgAlSi}_{4} \mathrm{O}_{10}(\mathrm{OH})_{2}\right]$ e hematita $\left(\mathrm{Fe}_{2} \mathrm{O}_{3}\right)$, típicas das argilas da região. Assim como a argila, pode-se

Tabela IV - Características da argila de Candeias, BA.

[Table IV - Characteristics of clay from Candeias, Bahia.]

\begin{tabular}{cccccccc}
\hline \multirow{2}{*}{ Composição química (\%) } & $\mathrm{SiO}_{2}$ & $\mathrm{Al}_{2} \mathrm{O}_{3}$ & $\mathrm{Fe}_{2} \mathrm{O}_{3}$ & $\mathrm{~K}_{2} \mathrm{O}$ & $\mathrm{TiO}_{2}$ & $\mathrm{MgO}$ & $\mathrm{PF}$ \\
& 41,25 & 30,75 & 11,94 & 4,77 & 1,73 & 1,65 & 7,70 \\
\hline Composição minerológica & Quartzo & \multicolumn{2}{c}{ Muscovita } & Caulinita & Hematita \\
\hline
\end{tabular}



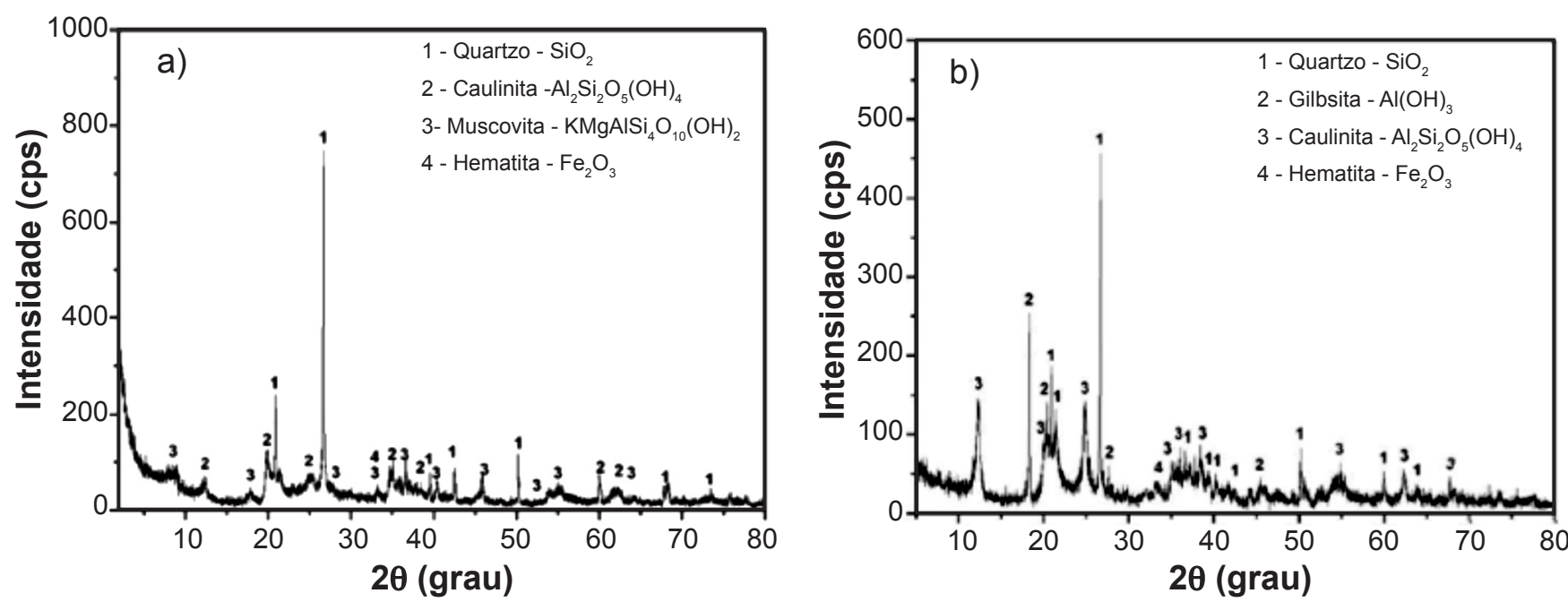

Figura 2: Difratogramas de raios X apresentando as fases cristalinas na amostra da argila (a) e do SCP (b). [Figure 2: XRD patterns showing the crystalline phases in the clay sample (a) and SCP sample (b).]

observar na Tabela I, que o SCP possuiu teores de $\mathrm{Al}_{2} \mathrm{O}_{3}$, $\mathrm{SiO}_{2}$ e $\mathrm{Fe}_{2} \mathrm{O}_{3}$ relativamente elevados, porém baixos teores de óxidos alcalinos fundentes típicos de argila caulinita [11]. A alta concentração de $\mathrm{Fe}_{2} \mathrm{O}_{3}$ nas matérias-primas em estudo corroborou para uma cor avermelhada das peças após queima.

Pela análise de DRX do SCP, Fig. 2b, foi constatada a presença de picos característicos de fases cristalinas, com predominância do quartzo $\left(\mathrm{SiO}_{2}\right)$, seguido da caulinita
$\left[\mathrm{Al}_{2} \mathrm{Si}_{2} \mathrm{O}_{5}(\mathrm{OH})_{4}\right]$ e da gibsita $\left[\mathrm{Al}(\mathrm{OH})_{3}\right]$, o que justificou a maior concentração de $\mathrm{Al}_{2} \mathrm{O}_{3}$ na sua composição química. Observou-se ainda a ocorrência do pico da hematita justificando a concentração significante de óxido de ferro na análise química; os óxidos de magnésio e zinco provavelmente encontraram-se na fase amorfa. As micrografias obtidas por MEV, Fig. 3, permitiram visualizar grãos com formatos irregulares e de diversos tamanhos com presença de elementos químicos diferenciados. Através do

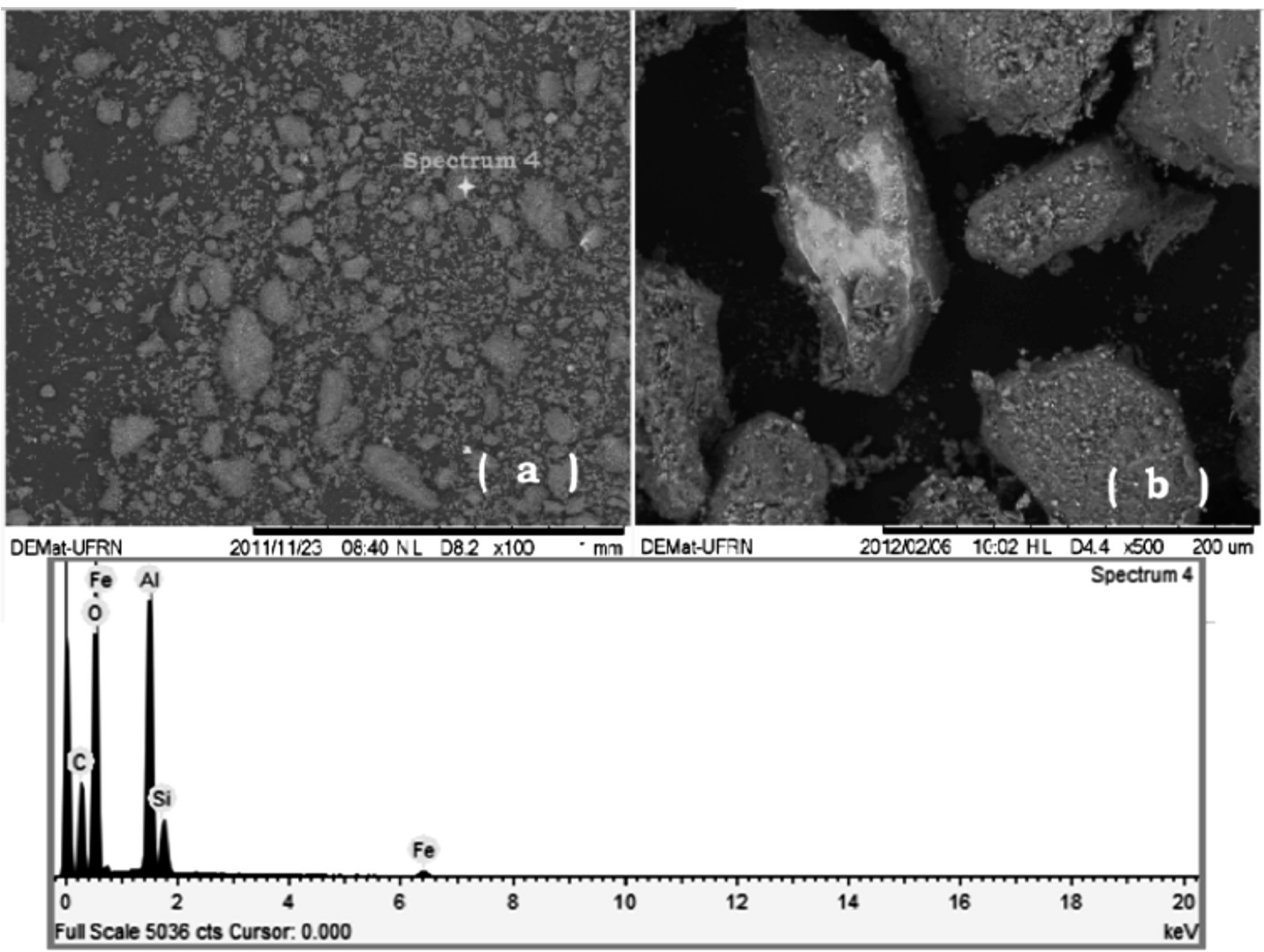

Figura 3: Micrografias obtidas por microscopia eletrônica de varredura das partículas do SCP. [Figure 3: SEM micrographs of SCP particles.] 
mapeamento por EDS, foram confirmados os dados obtidos na análise química por FRX.

A análise das curvas de distribuição granulométrica fracional e acumulada das Figs. 4a e 4b mostra que a argila possuiu maior porcentagem de partículas com diâmetro menor que $2 \mu \mathrm{m}$, com aproximadamente $19 \%$, contra $23 \%$ do SCP. Observou-se também que a argila apresentou, após moagem, granulometria entre 0,04 e $95 \mu \mathrm{m}$, sendo $18,77 \%$ do seu volume em uma granulometria inferior a 2 $\mu \mathrm{m}, 67,73 \%$ entre 2 e $20 \mu \mathrm{m}$ e $13,50 \%$ acima de $20 \mu \mathrm{m}$. Os $\mathrm{D}_{10}, \mathrm{D}_{50}$ e $\mathrm{D}_{90}$ apresentaram diâmetros de 1,12, 6,07 e 23,46 $\mu \mathrm{m}$, respectivamente, e diâmetro médio de partículas igual a $10,10 \mu \mathrm{m}$. A Fig. $4 \mathrm{~b}$ exibe o resultado da análise granulométrica do SCP, onde se verifica que o sedimento apresentou granulometria entre 0,04 e $95 \mu \mathrm{m}$, sendo $23,23 \%$ em volume inferior a $2 \mu \mathrm{m}, 58,15 \%$ entre 2 e $20 \mu \mathrm{m}$ e $18,62 \%$ superior a $20 \mu \mathrm{m}$. Os $\mathrm{D}_{10}, \mathrm{D}_{50}$ e $\mathrm{D}_{90}$ apresentaram diâmetros de 0,98, 5,82 e 31,41 $\mu \mathrm{m}$, respectivamente, tendo diâmetro médio de $11,62 \mu \mathrm{m}$.

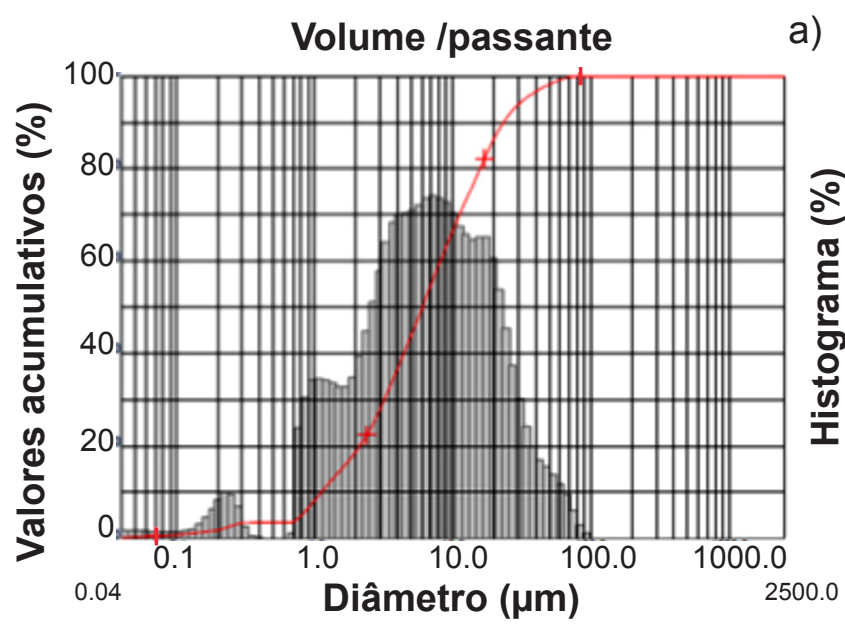

Volume /passante

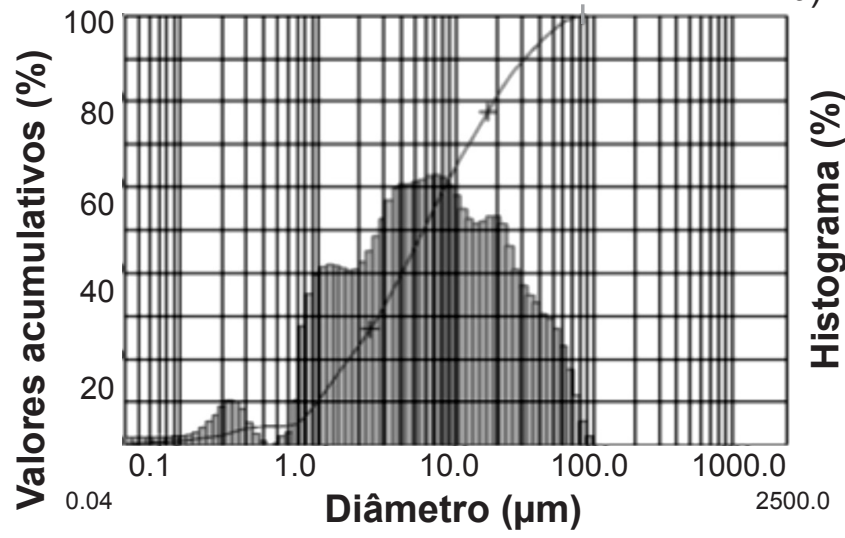

Figura 4: Distribuição granulométrica da argila (a) e do SCP (b). [Figure 4: Particle size distribution of clay (a) and SCP (b).]

A Tabela $\mathrm{V}$ contém as características das matériasprimas, com relação aos limites de consistência de Atterberg e distribuição granulométrica. Pode-se verificar que a argila e o SCP encontraram-se na faixa de alta plasticidade, com IP $\geq 15 \%$, segundo classificação adotada por Caputo [12], e granulometrias semelhantes, com pequena diferença no diâmetro médio. Como o tamanho de partículas pode se relacionar com o tipo de mineral e sua trabalhabilidade, que por sua vez está relacionada com a plasticidade, é possível que a utilização do SCP na massa argilosa, pouco tenha afetado a trabalhabilidade [11]. Por outro lado, embora os índices de plasticidade, tanto da argila como do SCP, sejam relativamente altos, esses não impactaram no comportamento de secagem dos corpos de prova em estudo, necessitando, porém, verificação em escala industrial.

A observação das curvas de TGA e ATD da argila, Fig. 5a, mostrou perda de massa de $10,15 \%$ entre 20 e $1200{ }^{\circ} \mathrm{C}$, sendo $3,04 \%$ de perda referente à água de hidratação, entre 0 e $160{ }^{\circ} \mathrm{C}$ com pico endotérmico em aproximadamente $67{ }^{\circ} \mathrm{C}$. Entre 160 e $400{ }^{\circ} \mathrm{C}$, a perda de $1,97 \%$ de massa correspondeu à queima da matéria orgânica, com pico exotérmico em aproximadamente $325^{\circ} \mathrm{C}$, e a perda de massa de $3,79 \%$ entre 400 e $600{ }^{\circ} \mathrm{C}$ correspondeu à eliminação de hidroxilas $(\mathrm{OH})$ com pico endotérmico em aproximadamente $488{ }^{\circ} \mathrm{C}$, indicando o processo de desidroxilação, transformação da caulinita em metacaulinita. Nesta mesma faixa de temperatura pôde-se observar, ainda, um pico em aproximadamente $576{ }^{\circ} \mathrm{C}$, indicando provavelmente a transformação polimórfica do quartzo alfa em quartzo beta. Na faixa de 600 a $1200{ }^{\circ} \mathrm{C}$, houve perda de $1,35 \%$ de massa, devido à perda de água de constituição ou estrutural.

A Fig. 5b apresenta as curvas termogravimétrica e termodiferencial do SCP, onde se pode observar um pico endotérmico entre 20 e $100{ }^{\circ} \mathrm{C}$ indicando perda de água livre [13], com $1,60 \%$ de perda de massa, que correspondeu à redução da água higroscópica incorporada naturalmente no sedimento. Entre $100 \mathrm{a} 400^{\circ} \mathrm{C}$ a perda de massa correspondeu à queima da matéria orgânica, com pico exotérmico em aproximadamente $243{ }^{\circ} \mathrm{C}$, seguido do pico endotérmico em aproximadamente $277{ }^{\circ} \mathrm{C}$, possível transformação pseudomórfica da gibsita, contribuindo para o aumento da refratariedade e perda de massa. Entre 400 e $600{ }^{\circ} \mathrm{C}$ a perda de massa deveu-se à eliminação de hidroxilas $(\mathrm{OH})$ e carbonatos $\left(\mathrm{CO}_{3}\right)$, transformação de hidróxidos e carbonatos em óxidos. Nesta faixa de temperatura ocorre a maior perda de água estrutural da caulinita, conforme indicou o pico endotérmico a $490,79{ }^{\circ} \mathrm{C}$, transformação da caulinita em metacaulinita; observou-se ainda em $570{ }^{\circ} \mathrm{C}$ um pico mau definido, indicando a transformação polimórfica do quartzo alfa em quartzo beta. $\mathrm{Na}$ faixa de 800 a $900{ }^{\circ} \mathrm{C}$, notou-se um pico exotérmico mau definido situado a aproximadamente $850{ }^{\circ} \mathrm{C}$; nesta temperatura ocorreu a formação da fase do espinélio da sílica-alumina. Sua composição, dado o pequeno tamanho das partículas, foi de difícil determinação, mas encontrou-se na faixa entre $\mathrm{Al}_{2} \mathrm{O}_{3}$ e $3 \mathrm{Al}_{2} \mathrm{O}_{3} \cdot 2 \mathrm{SiO}_{2}$ (alumina e mulita). A aproximadamente $1040{ }^{\circ} \mathrm{C}$ apresentou um pico exotérmico, mau definido, indicando a formação da fase da mulita mais cristobalita [14].

A partir da Tabela VI, que apresenta os valores médios dos resultados da retração linear de queima, absorção de água e do módulo de ruptura à flexão dos corpos sinterizados, 
Tabela V - Limites de consistência de Atterberg e distribuição granulométrica das matérias-primas.

[Table $V$-Atterberg consistency limits and particle size distribution of raw materials.]

\begin{tabular}{cccccccc}
\hline Matéria-prima & \multicolumn{2}{c}{ Distribuição granulométrica (\% do volume passante) } & \multicolumn{3}{c}{ Limites de consistência } \\
& $<2 \mu \mathrm{m}$ & $2 \mu \mathrm{m} \leq \emptyset \leq 20 \mu \mathrm{m}$ & $>20 \mu \mathrm{m}$ & & LL (\%) & LP (\%) & IP \\
\hline Argila & 18,77 & 67,73 & 13,50 & 10,10 & 73 & 51 & 22 \\
SCP & 23,23 & 58,15 & 18,62 & 11,62 & 51 & 32 & 19 \\
\hline
\end{tabular}
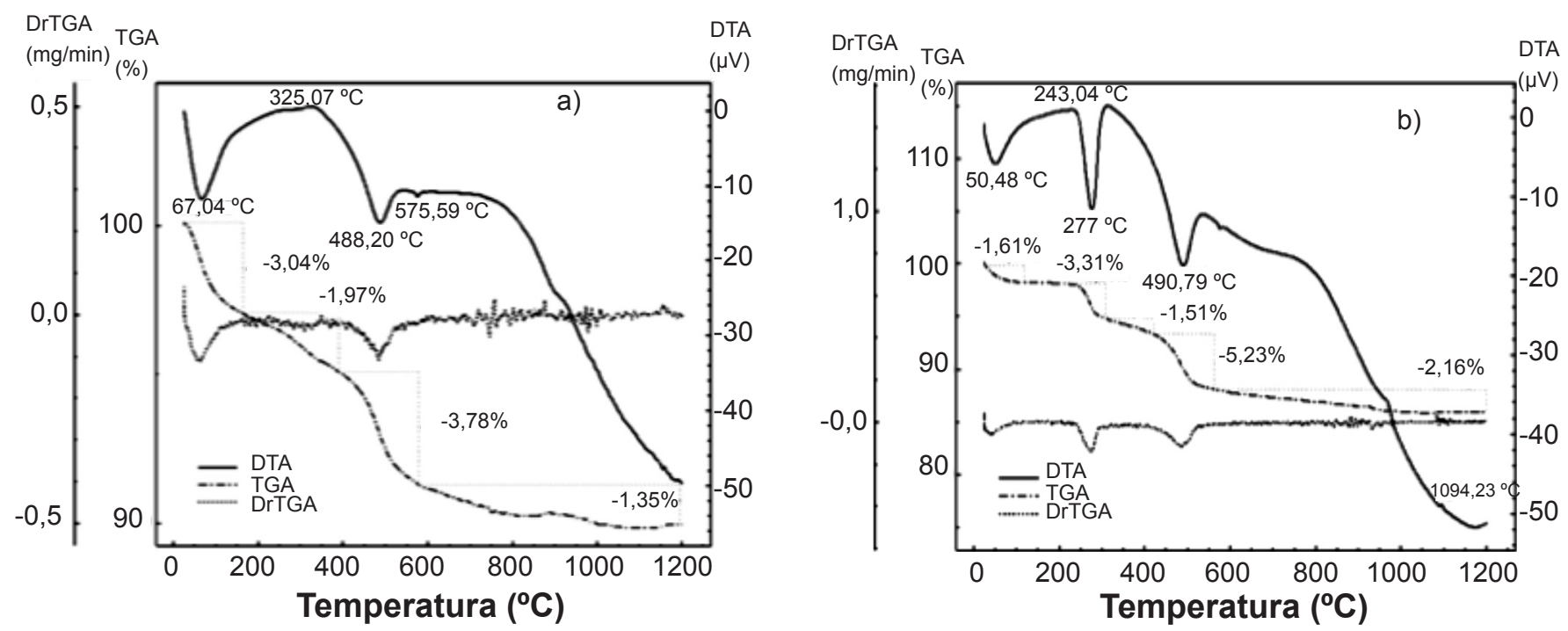

Figura 5: Curvas termogravimétrica e termodiferencial da argila (a) e do SCP (b).

[Figure 5: Thermogravimetric and thermodifferential curves of clay (a) and SCP (b).]

foram elaborados seus respectivos gráficos, para as diversas formulações conforme Fig. 6. Nota-se que a partir dos valores médios contidos na Tabela VI, foi possível identificar os efeitos composicionais e térmicos nas propriedades tecnológicas para cada formulação. Os corpos de prova com incremento maior que $10 \%$ em massa do SCP, formulações MR20, MR30 e MR40, apresentaram maior absorção de água e menor retração linear de queima, bem como menor resistência mecânica comparada com a formulação com $100 \%$ de argila (MR), enquanto que a formulação MR10, com $10 \%$ em massa de SCP, não apresentou variações significativas nas propriedades do produto final, adotandose essa como massa padrão na pesquisa de formulação de blocos intertravados cerâmicos. Na Fig. 6b, o gráfico mostra uma relação diretamente proporcional entre o aumento da dosagem do SCP e o aumento da propriedade de absorção de água (AA). Tomando-se como base as Normas ABNT NBR15310/2005 [15] e NBR 7170/1983b [16] constatou-se que a AA de todas as formulações e em todas as condições de queima, com exceção da MR40 nas temperaturas de 850 e $950{ }^{\circ} \mathrm{C}$, apresentou valores abaixo do valor limite máximo de $20 \%$, atribuído para a fabricação de telhas e tijolos, assim como todas atenderam à fabricação de blocos estruturais e de vedação, segundo as normas NBR 15270-1 e 15270-2 da ABNT com $\mathrm{AA} \leq 22 \%$. Como pode ser observado, valores maiores que $10 \%$ em massa do SCP na massa argilosa

Tabela VI - Resultados das propriedades tecnológicas das formulações após diferentes temperaturas de queima. [Table VI - Results of the technological properties of formulations after different firing temperatures.]

\begin{tabular}{cccccccccc}
\hline & \multicolumn{3}{c}{$850{ }^{\circ} \mathrm{C}$} & \multicolumn{3}{c}{$950{ }^{\circ} \mathrm{C}$} & \multicolumn{3}{c}{$1050{ }^{\circ} \mathrm{C}$} \\
Formulação & $\begin{array}{c}\text { RLq } \\
(\%)\end{array}$ & $\begin{array}{c}\text { AA } \\
(\%)\end{array}$ & $\begin{array}{c}\text { MRF } \\
(\mathrm{MPa})\end{array}$ & $\begin{array}{c}\text { RLq } \\
(\%)\end{array}$ & $\begin{array}{c}\text { AA } \\
(\%)\end{array}$ & $\begin{array}{c}\text { MRF } \\
(\mathrm{MPa})\end{array}$ & $\begin{array}{c}\text { RLq } \\
(\%)\end{array}$ & $\begin{array}{c}\text { AA } \\
(\%)\end{array}$ & $\begin{array}{c}\text { MRF } \\
(\mathrm{MPa})\end{array}$ \\
\hline MR & 0,61 & 16,16 & 8,17 & 2,02 & 13,49 & 10,76 & 3,58 & 10,39 & 14,09 \\
MR10 & 0,57 & 16,92 & 7,98 & 1,88 & 13,10 & 10,35 & 3,50 & 11,01 & 14,12 \\
MR20 & 0,33 & 18,27 & 5,45 & 0,53 & 17,98 & 6,24 & 2,96 & 14,42 & 6,47 \\
MR30 & 0,28 & 19,58 & 3,83 & 0,36 & 18,78 & 3,85 & 2,50 & 16,02 & 4,19 \\
MR40 & 0,25 & 20,29 & 3,80 & 0,28 & 20,01 & 3,81 & 2,24 & 17,67 & 3,86 \\
\hline
\end{tabular}

RLq - retração linear de queima; AA - absorção de água; $M R F$ - módulo de ruptura à flexão. 

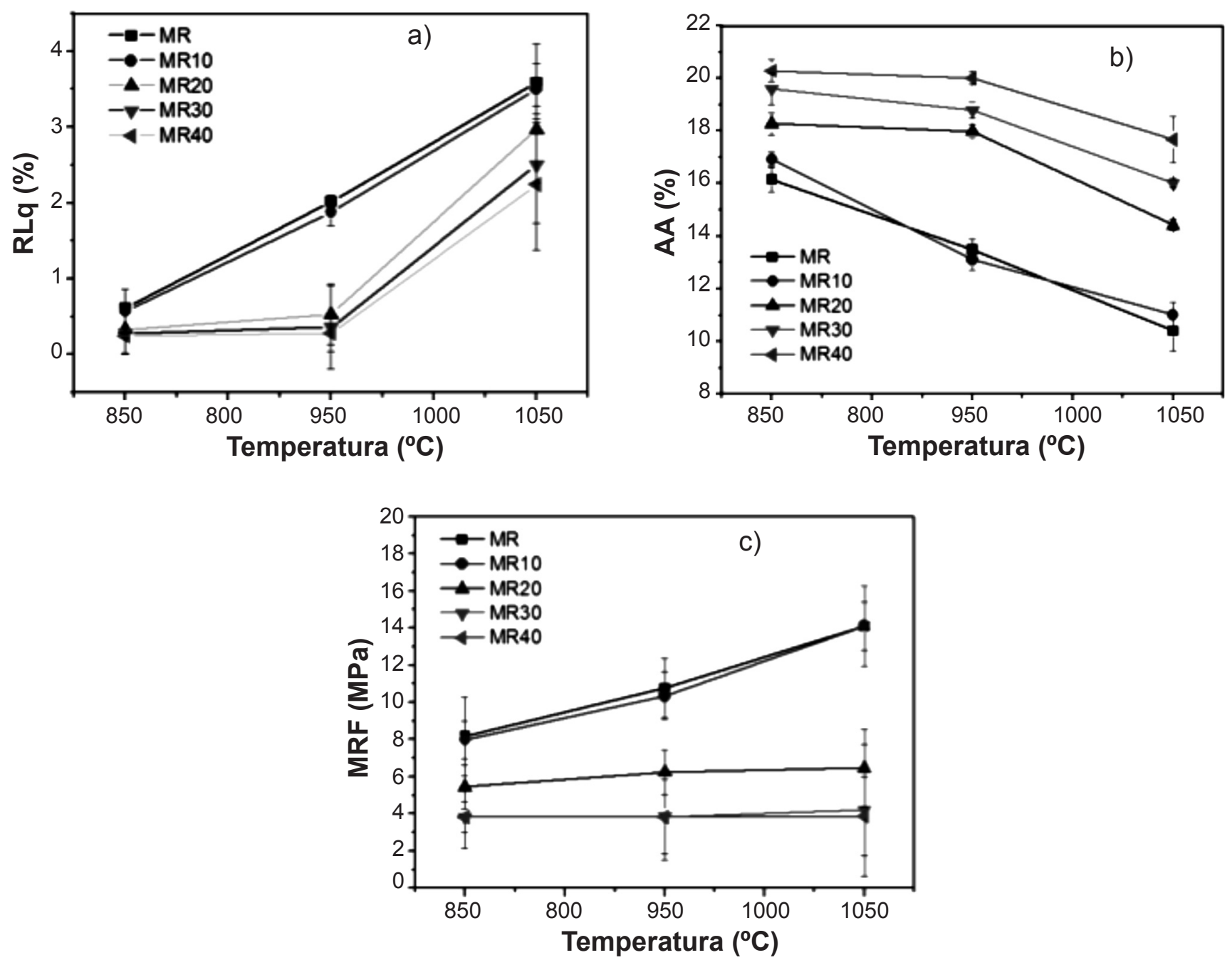

Figura 6: Gráficos de retração linear de queima (a), absorção de água (b) e módulo de ruptura à flexão (c) das composições em função da temperatura de queima.

[Figure 6: Graphs showing the firing shrinkage (a), water absorption (b), and modulus of rupture (c) of compositions according to the firing temperature.]

acarretaram maiores valores de absorção, o que pode ser atribuído ao caráter predominante caulinítico do sedimento e à elevada perda de massa na queima, face ao alto teor de argilominerais [17] e pela volatilização da matéria orgânica existente no sedimento, aumentando a porosidade aberta das peças cerâmicas.

As normas para tijolos e blocos de vedação não especificam valores de tensão ou módulo de ruptura à flexão, mas de resistência à compressão uniaxial. Uma vez que os limites de resistência à tração dos materiais cerâmicos valem aproximadamente $1 / 10$ de suas resistências à compressão e considerando que a fratura ocorre na face do corpo de prova sob tração, o ensaio de flexão é um substituto razoável para o ensaio de tração [18]. Assim, ressalta-se que a formulação com $10 \%$ em massa de SCP, e queima entre 850 e 1050 ${ }^{\circ} \mathrm{C}$, pode ser utilizada para a fabricação de tijolos, blocos de vedação e telhas, uma vez que atende as especificações exigidas por normas, tanto na absorção de água, como na resistência mecânica [8-18], assim como as demais formulações na fabricação de tijolos e blocos de vedação, exceto a MR40, nas queimas a 850 e $950{ }^{\circ} \mathrm{C}$, apenas para a fabricação de blocos de vedação. Com objetivo de validação dessa relação entre a resistência à compressão e a resistência à tração [18], e como a formulação adotada para a massa padrão foi a MR10, realizou-se o ensaio de resistência à compressão uniaxial em conformidade com a Norma NBR6460/1983 [19], em virtude da quantidade disponível do material de pesquisa, e os resultados obtidos foram comparados com os valores do MRF da formulação

Tabela VII - Comparativo dos resultados da resistência à compressão (Rc) e MRF da formulação MR10.

[Table VII - Comparison of results of compressive strength (Rc) and MOR of MR10 formulation.]

\begin{tabular}{ccc}
\hline $\begin{array}{c}\text { Temperatura de queima } \\
\left({ }^{\circ} \mathrm{C}\right)\end{array}$ & $\begin{array}{c}\mathrm{Rc} \\
(\mathrm{MPa})\end{array}$ & $\begin{array}{c}\mathrm{MRF} \\
(\mathrm{MPa})\end{array}$ \\
\hline 850 & 18,16 & 7,98 \\
950 & 26,25 & 10,35 \\
1050 & 31,78 & 14,12 \\
\hline
\end{tabular}


Tabela VIII - Resultados dos testes de solubilização e lixiviação das formulações. [Table VIII - Results of waste extraction and leaching tests of the formulations.]

\begin{tabular}{cccccc}
\hline Formulação & \multicolumn{4}{c}{ Solubilização (mg/L) } & \multicolumn{4}{c}{ Lixiviação (mg/L) } & Classificação \\
\hline & Mn & Zn & Mn & Zn & NBR 10004/04 \\
MR10 & ND & ND & ND & ND & Classe II-B \\
MR20 & ND & ND & ND & ND & Classe II-B \\
MR30 & $<0,01$ & ND & ND & ND & Classe II-B \\
MR40 & $<0,01$ & ND & ND & ND & Classe II-B \\
\hline Limite & 0,1 & 5,0 & NE & NE & NE - Não existe \\
NBR10004/04 & \multicolumn{2}{c}{ Anexo G } & Anexo F & ND - Não detectado \\
\hline
\end{tabular}

MR10, conforme Tabela VII. Como pode ser observado, houve um aumento do valor para a resistência à compressão (Rc) comparada ao valor do módulo de ruptura à flexão (MRF) em todas as temperaturas de queima. Praticamente os valores para $\mathrm{RC}$ foram mais que o dobro dos valores de MRF, podendo assim aceitar os valores do MRF como parâmetro para determinar a resistência à compressão com margem de segurança.

Para o processo de obtenção do extrato solubilizado e de lixiviação das peças cerâmicas sinterizadas, referentes às formulações MR10, MR20, MR30 e MR40, cujas composições possuem o SCP, foram utilizados os corpos de prova na forma retangular com dimensões de $60 \mathrm{~mm} \times 20 \mathrm{~mm}$. Os corpos de prova de cada formulação foram reduzidos até partículas abaixo de $9,5 \mathrm{~mm}$ (peneira ABNT 3/8"). O ensaio de lixiviação foi realizado em conformidade à norma $\mathrm{ABNT}$ NBR 10005/04, utilizando água destilada e ácido acético glacial como agente lixiviante. O ensaio de solubilização foi realizado segundo a norma ABNT NBR 10006/04, com o objetivo de avaliar o grau de encapsulamento do manganês e zinco na matriz cerâmica, reduzindo a capacidade de transferência ao meio ambiente. As concentrações dos metais analisados, nos extratos lixiviados e solubilizados dos corpos de prova em todas as formulações, ficaram abaixo dos limites definidos pela NBR 10004/2004 da ABNT [2], sendo classificado como não perigoso e inerte - Classe II-B, conforme Tabela VIII.

\section{CONCLUSÕES}

Com base nos resultados obtidos, verificou-se que os ensaios característicos do sedimento proveniente de dragagem de canais pluviais (SCP) revelaram tratar-se de uma argila caulinítica, apresentando em sua constituição mineralógica, além da fase caulinita, quartzo, gibsita e hematita. A mistura do SCP com a argila, na proporção de $10 \%$ e $90 \%$ em massa, respectivamente, não proporcionou variações significativas das propriedades do produto final, comparada com a massa argilosa pura, adotando-se essa como massa padrão para o estudo de formulação cerâmica para blocos intertravados. Entretanto, as formulações com SCP acima de $10 \%$ em massa proporcionaram aumento na absorção de água, contribuindo com a diminuição da retração linear de queima e da resistência mecânica. A pesar da adição do SCP na matriz cerâmica, com teores acima de $10 \%$ em massa, contribuir para diminuição da resistência mecânica das peças sinterizadas, comparadas com a massa pura, é possível sua aplicação nos produtos cerâmicos, mediante os pré-requisitos exigidos nas normas, por agregar-lhes valor econômico, contribuindo para redução de problemas ambientais gerados pelo descarte do sedimento (lama dragada) e da extração da matéria-prima (argila).

\section{AGRADECIMENTOS}

Os autores agradecem ao CNPq e à CAPES pelo apoio financeiro e, também, às instituições de ensino UFRN e IFBA pelo uso dos laboratórios.

\section{REFERÊNCIAS}

[1] F.G. da Rosa, M.V. Folgueras, A.L. Longo, A. Cechenel, A.P.N. de Oliveira, D. Hotza, O.E. Alarcon, Anais do XLIII Congresso Brasileiro de Cerâmica, Florianópolis, SC (1999) 9601 .

[2] ABNT - Associação Brasileira de Normas Técnicas, NBR 10004, "Resíduos Sólidos - Classificação", Rio de Janeiro, RJ (2004).

[3] E. Santos, J.A.G. de Pinho, L.R.S. Moraes, T. Fischer, $O$ caminho das águas: bacias hidrográficas, bairros e fontes, Salvador: CIAGS/UFBA; SEMA, Coleção Gestão Social (2010) 486p.

[4] Conselho Nacional do Meio Ambiente - CONAMA Resolução 344 de 2004, Diretrizes gerais e procedimentos mínimos para a avaliação do material a ser dragado em águas jurisdicionais brasileiras. Publicação DOU n ${ }^{\circ} 087$, de 07/05 (2004) 56-57.

[5] Instituto Nacional de Tecnologia - INT, "Panorama da indústria de cerâmica vermelha no Brasil", Rio de Janeiro (2012) 83.

[6] O.C. Santos, "Influências da adição de rejeitos cerâmicas nas propriedades de cerâmica vermelha da região do Recôncavo Baiano", Diss. Mestrado, UFRN, Natal (2007).

[7] P.S. Santos, Ciências e Tecnologia de Argilas, Vol. 1, 2. ed. S. Paulo, Editora Edgard Blucher (1989).

[8] ABNT - Associação Brasileira de Normas Técnicas, NBR 15270-1, "Componentes cerâmicos - parte-1, Blocoscerâmicos para alvenaria de vedação - Terminologia e 
requisitos", Rio de Janeiro, RJ (2005).

[9] ABNT - Associação Brasileira de Normas Técnicas, NBR 6459, "Determinação do limite de liquidez", Rio de Janeiro, RJ (1984).

[10] ABNT - Associação Brasileira de Normas Técnicas, NBR 7180, "Determinação do limite de plasticidade", Rio de Janeiro, RJ (1984).

[11] C.M.F. Vieira, E.T.A. Souza, S.N. Monteiro, Cerâmica 50 (2004) 254-260.

[12] H.P. Caputo, Mecânica dos solos e suas aplicações, Rio de Janeiro: LTC (1973).

[13] V. Beltran, E. Ferrando, J. García, E. Sánchez, Tile Brick Int. 11, 3 (1995) 169.

[14] I.M. Gueto, Tecnologia de los materiales cerâmicos, Madrid: Diaz de Santos (2005).
[15] ABNT - Associação Brasileira de Normas Técnicas, NBR 15310, "Componentes cerâmicos - Telhas- Terminologia, requisitos e métodos de ensaio", Rio de Janeiro, RJ (2005). [16] ABNT - Associação Brasileira de Normas Técnicas, NBR 7170, "Tijolo maciço cerâmico para alvenaria especificação", Rio de Janeiro, RJ (1983).

[17] S.N. Monteiro, C.M.F. Vieira, Tile Brick Int. 18, 3 (2002) 152.

[18] W.D. Callister Jr., Ciência e Engenharia de Materiais: uma introdução. 7. ed. Rio de Janeiro: LTC, 2008.

[19] ABNT - Associação Brasileira de Normas Técnicas, NBR 6460, "Tijolo maciço cerâmico para alvenaria Verificação da resistência à compressão", Rio de Janeiro, RJ (1983).

(Rec. 03/12/2015, Rev. 21/02/2016, 19/04/2016, 02/07/2016, Ac. 03/07/2016) 